(2) Open Access Full Text Article

\title{
Resveratrol inhibits the proliferation of A549 cells by inhibiting the expression of $\mathrm{COX}-2$
}

This article was published in the following Dove Press journal:

OncoTargets and Therapy

\author{
Xia $\mathrm{Li}^{\prime}$ \\ Fang $\mathrm{Li}^{\prime}$ \\ Fangfang Wang ${ }^{2}$ \\ Jinfeng $\mathrm{Li}^{2}$ \\ Cunzhi Lin $^{2}$ \\ Jianxin $\mathrm{Du}^{2}$ \\ 'Respiratory Department of Internal \\ Medicine, Rizhao People's Hospital \\ of Shandong Province, Rizhao, \\ Shandong, 276800, China; ${ }^{2}$ Pulmonary \\ Department, Affiliated Hospital \\ of QingDao University, Qingdao, \\ Shandong, 266003, China
}

Correspondence: Jianxin Du Pulmonary Department, Affiliated Hospital of QingDao University, Number 16, Jiangsu Road, Qingdao, Shandong, 266003, China

Tel +86 I805323 5I87

Email dujianxin357@163.com
Purpose: The aim was to investigate resveratrol effects on A549 cells proliferation.

Methods: A total of 104 lung adenocarcinoma tissues and nontumor tissues were collected. BEAS-2B cells were cultured in RPMI 1640 medium (group A). A549 cells were treated with RPMI 1640 medium containing different resveratrol concentrations. A549 cells were transfected and grouped as follows: blank group, siRNA-negative control group, siRNA-COX-2 group and resveratrol + siRNA-COX-2 group. qRT-PCR and Western blot were conducted to detect $C O X-2$ expression. MTT assay, soft agar clone assay and flow cytometry were performed to assess proliferation and cell cycle.

Results: The relative expression of $C O X-2 \mathrm{mRNA}$ was significantly increased in lung adenocarcinoma tissues $(P<0.01)$ and it was closely related with clinical stages. Resveratrol at $60 \mu \mathrm{mol} / \mathrm{L}$ significantly inhibited A549 cells proliferation, S phase cells proportion and $C O X-2$ expression $(P<0.01)$. COX-2 expression in siRNA-COX-2 group was significantly lower than that in blank group and siRNAnegative control group $(P<0.01)$. $\mathrm{OD}_{570}$ values, colony formation rate and $\mathrm{S}$ phase cells proportion of resveratrol + siRNA-COX-2 group were much lower than those of other groups $(P<0.01)$.

Conclusion: Resveratrol inhibits A549 cells proliferation by inhibiting $C O X-2$ expression.

Keywords: resveratrol, $C O X-2$ expression, A549 cell, proliferation

\section{Introduction}

Lung cancer, one of the most commonly diagnosed aggressive malignancies, is accounting for more than 1 million deaths worldwide. ${ }^{1}$ According to the statistics, of all lung cancer patients, 85\% are non-small-cell lung cancer (NSCLC) and 80\% of lung cancer-related deaths are caused by NSCLC. ${ }^{2}$ Pathogenic factors of NSCLC are complex, such as smoking and air pollution. In most cases, the prognosis of NSCLC is very poor. Greatly improved treatment strategies of NSCLC have been developed, such as surgical resection, radiotherapy and chemotherapy. ${ }^{3-6}$ In addition, drug therapy is also a major treatment for NSCLC. ${ }^{7}$ The anti-NSCLC drugs that have been used clinically are also diverse, but the effect is still not satisfactory. Therefore, it is urgent to find an effective therapeutic drug in the treatment of NSCLC.

Resveratrol, a polyphenol compound, is derived from polygonum cuspidatum. ${ }^{8}$ Studies have shown that it has a variety of therapeutic effects, such as antiinflammatory, antihyperlipidemia, antibacterial, and antiapoptotic effects. ${ }^{9-11}$ More importantly, resveratrol has been reported to have anticancer effects in cancers such as gastric cancer, breast cancer, pancreatic cancer, as well as colon cancer. ${ }^{8,12-14}$ In addition, the specific mechanisms of its anticancer function remain elusive and its application in treating NSCLC is still rare. Cyclooxygenase-2 $(\mathrm{COX}-2)$ is an inducible enzyme, and in most cases, it is rarely expressed in normal tissue cells. ${ }^{15}$ However, $C O X-2$ expression will be increased if cells are exposed to stimulation such as endotoxins and oncogenes. In addition, inflammatory 
reaction and damaged repair processes of cells can also induce overexpression of $C O X-2 .{ }^{16} \mathrm{COX}-2$ is reported to be upregulated in a variety of tumors, such as colorectal cancer, breast cancer, as well as ovarian cancer, and mechanism might be inhibiting the expression of $\mathrm{COX}-2 \cdot{ }^{17-19}$

We realized that there was little literature about $C O X-2$ affecting the development of NSCLC. The efficiency and mechanism of resveratrol in the treatment of NSCLC have not yet been studied. So in this study, we investigated the effect of resveratrol on proliferation of A549 cells to provide guidance for the clinical treatment of NSCLC.

\section{Materials and methods}

\section{Collection of lung adenocarcinoma tissue samples}

From May 2015 to March 2017, a total of 239 tissue samples of patients who were admitted to our hospital for lung adenocarcinoma treatment were collected. Patients who met the following criteria were included in the study: 1) patients who were firstly diagnosed with lung adenocarcinoma; 2) patients who did not have previously history of resveratrol medication; 3) patients who voluntarily joined the study and signed informed consent. Exclusion criteria were as follows: 1) patients with other serious organic disease; 2) lactating and pregnant women were excluded; and 3) patients who did not volunteer to join the study. Finally, 104 lung adenocarcinoma patients meeting the above criteria were included. Of these patients, 26 cases were in stage I, 31 cases were in stage II, and 47 cases were in stage III. Tumor tissues and nontumor tissues of these patients were obtained for the detection of $C O X-2$ expression. This study has been approved by the ethics committee of the Affiliated Hospital of QingDao University. Written informed consent was obtained from all participants.

\section{Cell culture and grouping}

Human lung cancer cell line (A549 cells) and human normal lung epithelial cell line (BEAS-2B cells) (purchased from American Type Culture Collection, Manassas, VA, USA) were cultured in RPMI 1640 medium and the medium was containing 10\% fetal bovine serum (FBS; Thermo Fisher Scientific, Waltham, MA, USA). Then these cells were incubated in an incubator with $5 \% \mathrm{CO}_{2}$ at $37^{\circ} \mathrm{C}$.

When these cells had grown to the logarithmic growth phase, they were collected and prepared as cell suspensions at a density of $1 \times 10^{5}$ cells $/ \mathrm{mL}$. For BEAS-2B cell suspensions, they were continuously cultured in conventional RPMI 1640 medium and were named as Group A. For A549 cell suspensions, they were cultured in RPMI 1640 medium containing different concentrations of resveratrol. Resveratrol concentrations were $0 \mu \mathrm{mol} / \mathrm{L}, 20 \mu \mathrm{mol} / \mathrm{L}, 40 \mu \mathrm{mol} / \mathrm{L}$, $60 \mu \mathrm{mol} / \mathrm{L}, 80 \mu \mathrm{mol} / \mathrm{L}$ respectively, and according to the concentration of resveratrol, they were named as Group B, Group $\mathrm{B}_{20}$, Group $\mathrm{B}_{40}$, Group $\mathrm{B}_{60}$, Group $\mathrm{B}_{80}$ in turn. Cells in the above groups were inoculated in 96-well plates with a volume of $200 \mu \mathrm{L}$ per well and incubated for $12 \mathrm{~h}, 24 \mathrm{~h}$, $48 \mathrm{~h}$ and $72 \mathrm{~h}$ at $37^{\circ} \mathrm{C}, 5 \% \mathrm{CO}_{2}$ incubators.

\section{Cell transfection and grouping}

Four groups were set in this section: blank group, siRNAnegative control group, siRNA-COX-2 group, and resveratrol+ siRNA-COX-2 group. For cells in blank group, they were A549 cells cultured in conventional RPMI 1640 medium. For siRNA-negative control group, A549 cells successfully transfected by siRNA negative control were cultured in conventional RPMI 1640 medium. For siRNA-COX-2 group, A549 cells successfully transfected by siRNA-COX-2 were cultured in conventional RPMI 1640 medium (the COX-2 siRNA sequence is as follows: target sequence: $5^{\prime}$-GCTGGG AAG CCT TCT CTA A-3'; sense strand: 5'-GCUGGG AAG CCU UCU CUA AdT dT-3'; antisense strand: $3^{\prime}$-dTd TCG ACC CUU CGG AAG AGA UU-5'). For resveratrol + siRNA-COX-2 group, they were A549 cells successfully transfected by siRNA-COX-2, and were cultured in RPMI 1640 medium containing $60 \mu \mathrm{mol} / \mathrm{L}$ resveratrol. Cells in the above groups were prepared as cell suspensions at a density of $1 \times 10^{5}$ cells $/ \mathrm{mL}$ and were inoculated in 6-well plates with a volume of $1,000 \mu \mathrm{L}$ per well.

\section{MTT assay}

Cells of each group were removed from the incubator and $20 \mu \mathrm{L}$ of MTT solution was added into each well $(5 \mathrm{mg} / \mathrm{mL}$, Sigma Aldrich). The liquid in each well was discarded after incubation at $37^{\circ} \mathrm{C}$ for $5 \mathrm{~h}$ in a $5 \% \mathrm{CO}_{2}$ incubator. Then $150 \mu \mathrm{L}$ DMSO was added to each well and the plate was shaken for $10 \mathrm{~min}$ to facilitate dissolution of the crystals. Absorbance $\left(\mathrm{OD}_{570}\right)$ of each well was measured at $570 \mathrm{~nm}$ at the enzyme-linked immunosorbent assay. Absorbance values of each well were repeated three times to take the average.

\section{Quantitative reverse transcription polymerase chain reaction (qRT-PCR)}

Tissue samples were ground in liquid nitrogen. Total RNA was extracted from these tissues and cells of each group. qRT-PCR was used to detect the expression of $\mathrm{COX}-2$ mRNA. qRT-PCR reaction was conducted as follows: predenaturation for $10 \mathrm{~min}$ at $95^{\circ} \mathrm{C}$, denaturation for $10 \mathrm{~s}$ 
at $95^{\circ} \mathrm{C}$, annealing for $20 \mathrm{~s}$ at $60^{\circ} \mathrm{C}$, extension for $34 \mathrm{~s}$ at $72^{\circ} \mathrm{C}$. The process consisted of 40 cycles and glyceraldehyde 3-phosphate dehydrogenase $(G A P D H)$ was set as internal reference. The amplification primers for the $C O X-2$ gene and GAPDH internal reference are shown in Table 1.

\section{Western blot analysis}

Cells were lysed by protein lysis method to obtain total protein of each group. Then $20 \mu \mathrm{L}$ protein sample solution was separated by sodium dodecyl sulfate polyacrylamide gel electrophoresis (SDS-PAGE) and transferred onto polyvinylidene fluoride membranes at $100 \mathrm{~mA}$ for $120 \mathrm{~min}$. After blocking by $5 \%$ skimmed milk, the membrane was placed in an incubator and incubated with rabbit antihuman COX-2 monoclonal antibody $(1: 1,000)$ overnight at $4^{\circ} \mathrm{C}$. The membrane was later washed with tris buffered saline with tween 20 for three times (10 $\mathrm{min} /$ time), and then horseradish peroxidase labeled mouse anti-rabbit polyclonal secondary antibody $(1: 5,000)$ was added before incubation at room temperature for $1 \mathrm{~h}$. Finally, color reagent was added for color development after washing by eluent for five times (10 $\mathrm{min} / \mathrm{time})$.

\section{Soft agar clone assay}

Soft agar clone assay was conducted to research cell proliferation capacity. Cells to be tested were collected in logarithmic growth phase and seeded in a 6-well plate at a density of $1 \times 10^{3}$ cells $/ \mathrm{mL}$ at $2 \mathrm{~mL}$ per well. These 6-well plates consisted of RPMI 1640 medium and 5\% agar. Then they were incubated for 20 days in a $5 \% \mathrm{CO}_{2}$ incubator at $37^{\circ} \mathrm{C}$. Clones containing $>50$ cells were counted under inverted microscope. The colony formation rate was calculated according to the following formula: Colony formation rate $=$ Number of colonies/Number of inoculated cells $\times 100 \%$.

\section{Flow cytometry analysis}

Cells were collected in logarithmic growth phase and inoculated in $60 \mathrm{~mm}$ culture plate. When the cell growth area reached $80 \%$ of the surface area of the culture plate,

Table I The amplification primers for the COX-2 gene and GAPDH internal reference

\begin{tabular}{ll}
\hline Name of primer & Sequences \\
\hline COX-2-F & AGCTAGCTAGGACTGATCGCTAC \\
COX-2-R & CGTAGTCGCGGCTAGCTAGCTAGC \\
GAPDH-F & GTCGATGGCTAGTCGTAGCATCGAT \\
GAPDH-R & TGCTAGCTGGCATGCCCGATCGATC \\
\hline
\end{tabular}

Abbreviation: GAPDH, glyceraldehyde 3-phosphate dehydrogenase. cells were collected after digestion with trypsin and washed twice with PBS. Then they were added into $1 \mathrm{~mL}$ of $70 \%$ precooled ethanol at $4^{\circ} \mathrm{C}$ for $12 \mathrm{~h}$ after discarding the supernatant. After centrifugation at $1,000 \mathrm{rpm}$ for $5 \mathrm{~min}$, cells were resuspended using $0.5 \mathrm{~mL}$ PBS. Iodized and RNaseA $(10 \mathrm{mg} /$ $\mathrm{mL}$ ) were added to a final concentration of $50 \mu \mathrm{g} / \mathrm{mL}$, and then incubated in a $37^{\circ} \mathrm{C}$ warm water bath for $30 \mathrm{~min}$ before cell cycle was measured by flow cytometry.

\section{Statistical analysis}

All data were processed by SPSS 18.0. Data were expressed as means $\pm \mathrm{SD}$ and the two-tailed Student's $t$-test was used for statistical comparison. $P<0.05$ was indicated that the difference was statistically significant.

\section{Results \\ COX-2 relative expression in lung adenocarcinoma was related to clinical stages}

qRT-PCR detection showed that $C O X-2$ mRNA relative expression in different stages of lung adenocarcinoma tissue samples was significantly higher than that in nontumor tissues $(P<0.01)$. Meanwhile, there was a significant difference in $C O X-2$ relative expression among different stages of lung adenocarcinoma tissues $(P<0.01)$. The relative expression of $C O X-2$ in stage III lung adenocarcinoma tissues was the highest, followed by stage II lung adenocarcinoma tissues. COX-2 relative expression in stage I lung adenocarcinoma tissues was the lowest, but it was still significantly higher than that in nontumor tissues $(P<0.01)$ (Figure 1). These results suggested that $C O X-2$ mRNA relative expression was significantly increased in lung adenocarcinoma tissues and it was closely related with clinical stages.

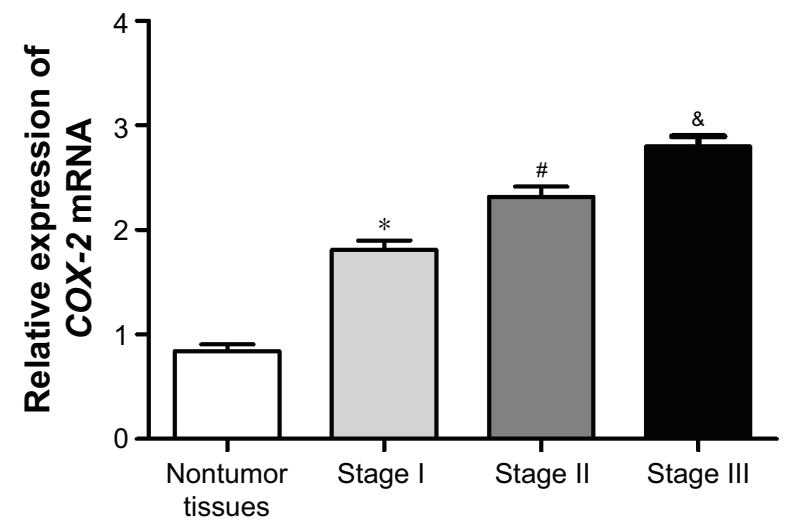

Figure I COX-2 mRNA relative expression in lung adenocarcinoma was related to the clinical stage. ${ }^{* P}<0.01$ or ${ }^{\# P}<0.01$ or ${ }^{\&} P<0.01$ when compared with $C O X-2$ mRNA relative expression in the other three groups. 


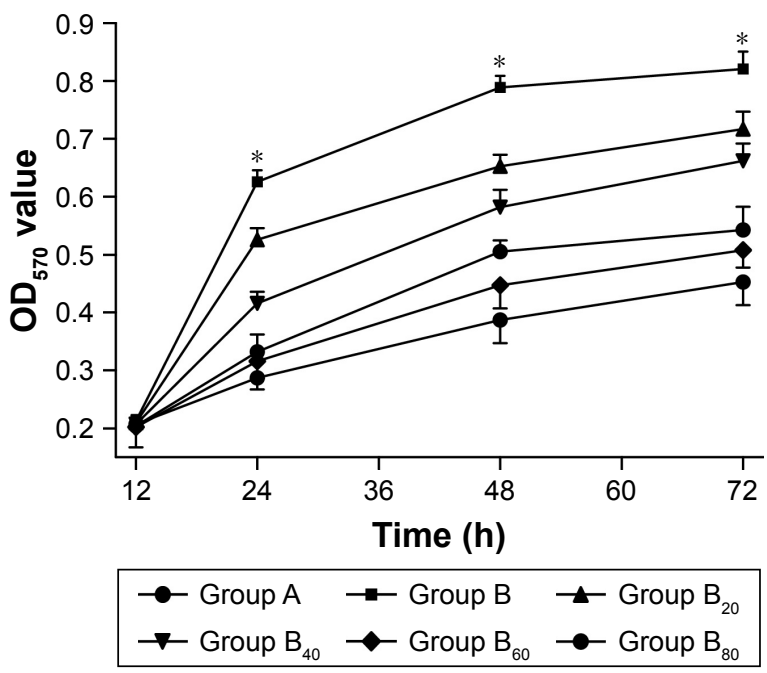

Figure 2 MTT assay was performed to detect the effect of resveratrol on A549 cell proliferation. ${ }^{*} P<0.01$ when compared with other groups at the same time.

Notes: For BEAS-2B cell suspensions, they were continuously cultured in conventional RPMI 1640 medium and were named as Group A. For A549 cell suspensions, they were cultured in RPMI 1640 medium containing different concentrations of resveratrol. Resveratrol concentrations were $0 \mu \mathrm{mol} / \mathrm{L}, 20$ $\mu \mathrm{mol} / \mathrm{L}, 40 \mu \mathrm{mol} / \mathrm{L}, 60 \mu \mathrm{mol} / \mathrm{L}$, and $80 \mu \mathrm{mol} / \mathrm{L}$, respectively, and according to the concentration of resveratrol, they were named as Group B, Group $B_{20}$, Group $B_{40}$, Group $B_{60}$, and Group $B_{80}$, respectively.

\section{The optimal concentration of resveratrol to inhibit A549 cell proliferation}

MTT assay was used to detect the effect of resveratrol on A549 cell proliferation (Figure 2). After $24 \mathrm{~h}$, the proliferation of Group B was significantly higher than that of other groups $(P<0.01)$. Different concentrations of resveratrol could significantly inhibit the proliferation of A549 cells. At a concentration of $20-60 \mu \mathrm{mol} / \mathrm{L}$, the inhibitory effect of resveratrol on A549 cells proliferation was gradually increased with the increase of resveratrol concentration, while it was a little decreased when resveratrol concentration was at $80 \mu \mathrm{mol} / \mathrm{L}$. The optimal concentration of resveratrol inhibiting A549 cell proliferation was $60 \mu \mathrm{mol} / \mathrm{L}$ (Figure 2).

\section{Resveratrol inhibited the malignant proliferation of A549 cells}

Soft agar cloning experiments were performed to investigate the effect of resveratrol on A549 cells malignant proliferation. The colony formation rate of Group B was the highest, which was significantly higher than that of Group A and Group $\mathrm{B}_{60}$ $(P<0.01)$. The colony formation rate of Group $\mathrm{B}_{60}$ was still higher than that of Group A, but is not statistically significant $(P>0.05)$ (Figure 3A and B).

\section{Resveratrol reduced the proportion of A549 cells in S phase}

Flow cytometry was conducted to determine the cell cycle. The proportion of $\mathrm{S}$ phase cells in Group B was significantly higher than that in Group A and Group $\mathrm{B}_{60}(P<0.01)$. In addition, $\mathrm{S}$ phase cells proportion in Group $\mathrm{B}_{60}$ was higher than that of Group A, but without statistically significant difference $(P>0.05)$ (Figure $4 \mathrm{~A}$ and $\mathrm{B})$.

\section{Resveratrol inhibited the expression of COX-2 in A549 cells}

qRT-PCR results showed that $C O X-2$ mRNA relative expression of A549 cells in Group B was significantly higher than that in Group A and Group $\mathrm{B}_{60}(P<0.01)$. The difference of $C O X-2$ mRNA relative expression between Group $\mathrm{B}_{60}$ and Group A was not statistically significant, even though A549 cells in Group $\mathrm{B}_{60}$ exhibited slightly higher $C O X-2$ mRNA relative expression (Figure 5A). The relative expression of COX-2 protein among the three groups also showed similar results (Figure 5B).

\section{Inhibitory effect of COX-2 siRNA on COX-2 expression}

After transfection, the relative expression of $\mathrm{COX}-2$ protein in siRNA-COX-2 group was significantly lower than that in
A

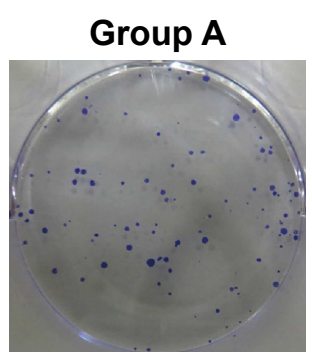

Group B

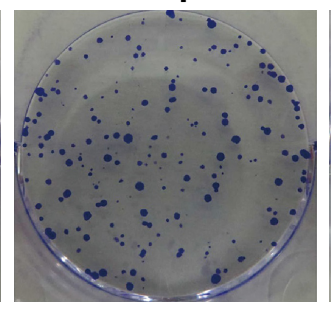

Group $B_{60}$

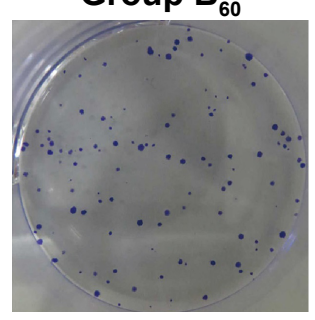

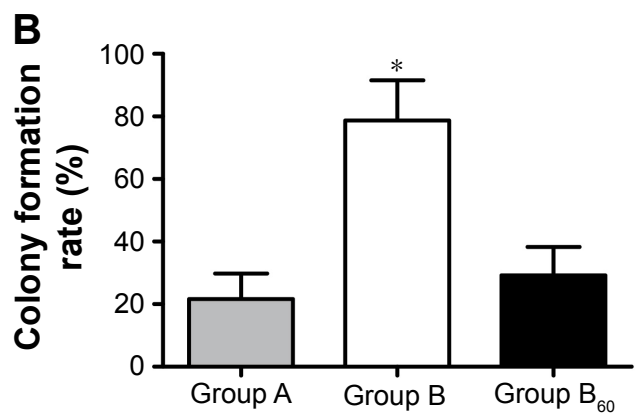

Figure 3 Effects of resveratrol on malignant proliferation of $A 549$ cells. (A) soft agar clone; (B) colony formation rate. $* P<0.01$ when compared with the other two groups. Notes: For BEAS-2B cell suspensions, they were continuously cultured in conventional RPMI 1640 medium and were named as Group A. For A549 cell suspensions, they were cultured in RPMI 1640 medium containing different concentrations of resveratrol. Group B had resveratrol concentration of $0 \mu \mathrm{mol} / \mathrm{L}$ and $\mathrm{Group} \mathrm{B}_{60}$ had resveratrol concentration of $60 \mu \mathrm{mol} / \mathrm{L}$. 

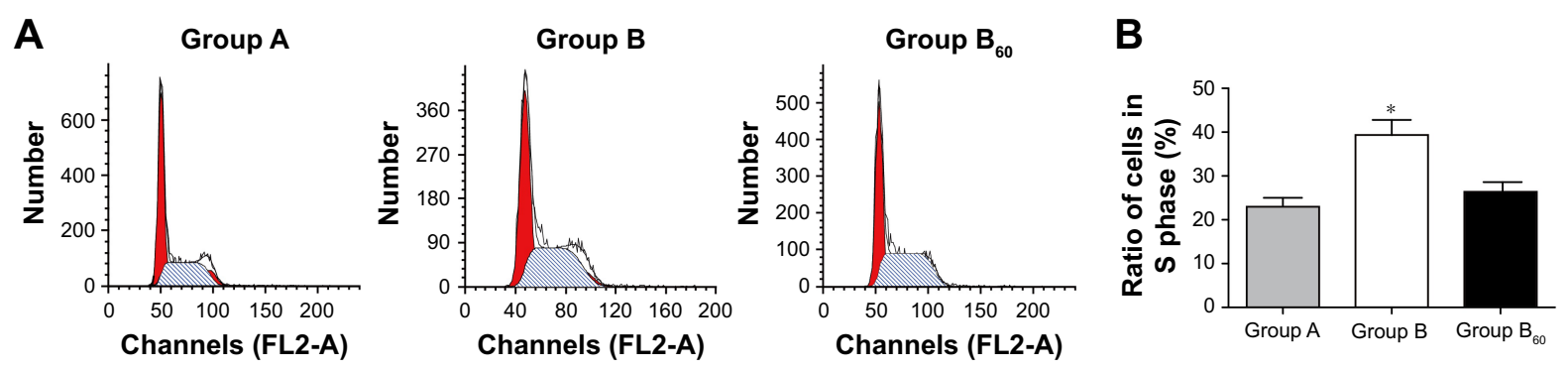

Figure 4 Effects of resveratrol on cell cycle of A549 cells. (A) Flow cytometry was performed to determine cell cycle. (B) Ratio of S phase A549 cell. *P<0.0I when compared with the other two groups.

Notes: For BEAS-2B cell suspensions, they were continuously cultured in conventional RPMI I640 medium and were named as Group A. For A549 cell suspensions, they were cultured in RPMI 1640 medium containing different concentrations of resveratrol. Group B had resveratrol concentration of $0 \mu$ mol/L and $\mathrm{Group} B$ had resveratrol concentration of $60 \mu \mathrm{mol} / \mathrm{L}$.

blank group and siRNA-negative control group $(P<0.01)$, while no significant difference was found in COX-2 protein relative expression between blank group and siRNA-negative control group (Figure 6).

\section{Resveratrol inhibited A549 cells proliferation by inhibiting the expression of COX-2}

MTT assay showed that at $24 \mathrm{~h}$, there was no significant difference in $\mathrm{OD}_{570}$ value among the four groups. However, at $48 \mathrm{~h}$ and $72 \mathrm{~h}$, the $\mathrm{OD}_{570}$ value of resveratrol group, siRNACOX-2 group, resveratrol + siRNA-COX-2 group were all significantly lower than that of siRNA-negative control group $(P<0.01)$. The $\mathrm{OD}_{570}$ values of resveratrol + siRNA-COX-2 group were the lowest all the time. And at $72 \mathrm{~h}, \mathrm{OD}_{570}$ value of resveratrol + siRNA-COX-2 group was remarkably lower than that of resveratrol group and siRNA-COX-2 group $(P<0.05)$ (Figure 7A).

Soft agar cloning experiments results showed that the colony formation rate of siRNA-negative control group was the highest. Colony formation rate of resveratrol group and siRNA-COX-2 group were both significantly lower than that of siRNA-negative control group $(P<0.01)$, but no significant difference was found in the colony formation rate between these two groups. Resveratrol + siRNA-COX-2 group had the lowest colony formation rate, which was significantly lower than that of siRNA-negative control group $(P<0.01)$ and also much lower than that of resveratrol group and siRNA-COX-2 group $(P<0.05)$ (Figure 7B).

Flow cytometry results showed that, compared with siRNA-negative control group, the proportion of $\mathrm{S}$ phase cells in resveratrol group, siRNA-COX-2 group, and resveratrol + siRNA-COX-2 group was significantly lower $(P<0.01)$. There was no significant difference in $\mathrm{S}$ phase cells proportion between resveratrol group and siRNA-COX-2 group $(P>0.05)$. In addition, the proportion of $\mathrm{S}$ phase cells in resveratrol + siRNA-COX-2 group was much lower than that in resveratrol group and siRNA-COX-2 group $(P<0.05)$ (Figure 7C).

\section{Discussion}

The effect of resveratrol on the proliferation of A549 cells and the underlying mechanism were studied here. Our results indicated that $C O X-2$ mRNA relative expression
A

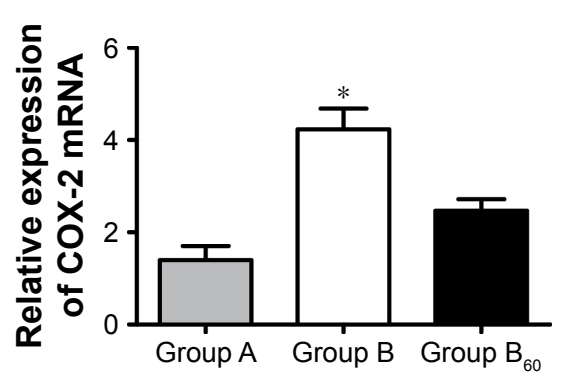

B

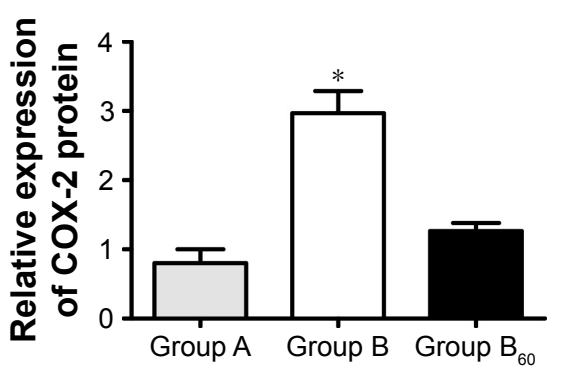

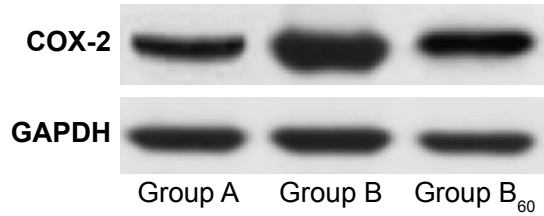

Figure 5 Effects of resveratrol on the expression of COX-2 in A549 cells. (A) Expression of COX-2 mRNA by qRT-PCR. (B) Expression of COX-2 protein by Western blot. $* P<0.01$ when compared with the other two groups.

Notes: For BEAS-2B cell suspensions, they were continuously cultured in conventional RPMI 1640 medium and were named as Group A. For A549 cell suspensions, they were cultured in RPMI 1640 medium containing different concentrations of resveratrol. Group B had resveratrol concentration of $0 \mu$ mol/L and $\mathrm{Group} B$ had resveratrol concentration of $60 \mu \mathrm{mol} / \mathrm{L}$.

Abbreviations: GAPDH, glyceraldehyde 3-phosphate dehydrogenase; qRT-PCR, quantitative reverse transcription polymerase chain reaction. 
A

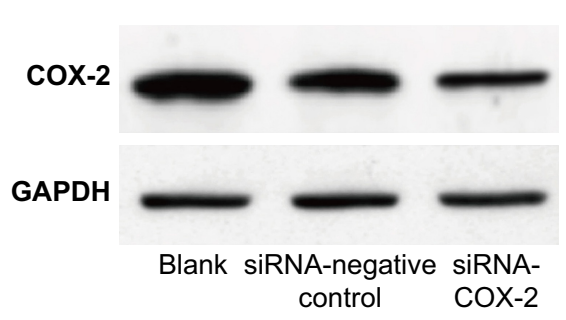

B

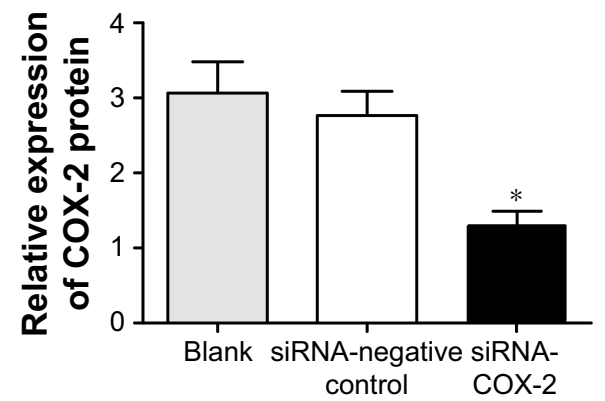

Figure 6 Silencing of COX-2 gene inhibits COX-2 protein expression. (A) Blotting of protein by Western blot. (B) Statistical data of protein by Western blot. *P $<0.0$ I when compared with the other two groups.

Abbreviation: GAPDH, glyceraldehyde 3-phosphate dehydrogenase.

had significantly increased in lung adenocarcinoma tissues and it was closely related with clinical stages. Resveratrol inhibited the proliferation of A549 cells in a concentrationdependent manner and the most significant effect of inhibition of proliferation was at a concentration of $60 \mu \mathrm{mol} / \mathrm{L}$. More importantly, this study further showed that resveratrol inhibited the proliferation of NSCLC cells by inhibiting the expression of $C O X-2$, which provided a new therapeutic target for the clinical treatment of NSCLC. In previous studies, researchers also found that resveratrol could inhibit proliferation and reduce S-phase cells proportion of other lung cancer cell lines, such as NCI H460, NCI H23, H466, H460, PC-9, H1975, H838 and H520 cells lines. ${ }^{18,20-22}$ This study was consistent with these previous studies.

It has been reported that more than 1.3 million patients suffered from lung cancer annually worldwide and approximately $85 \%$ of them underwent NSCLC with five-year survival rate of only $9 \%-15 \% .^{23,24}$ Surgical resection, chemotherapy and radiotherapy are the recommended standard first-line treatments for NSCLC, but complete radical treatment cannot be achieved by these traditional treatments and the 5-year survival rate of lung cancer patients after treatment has not been significantly improved. ${ }^{25}$ Therefore, gene targeting therapy for NSCLC has been clinically applied to a certain extent, which is able to achieve a radical treatment goal of NSCLC at the genetic level. $C O X-2$ is found to be overexpressed in a variety of tumor cells and many studies have shown that tumor development could be repressed by inhibiting the expression of $C O X-2$. Liu et $\mathrm{al}^{26}$ revealed that $C O X-2$ was involved in the development and progression of invasive breast cancer because their research found that mammary gland tumor genesis could be induced by upregulation of $C O X-2$. Other studies have also suggested that poor prognosis could occur if $C O X-2$ expression was greatly upregulated, such as breast cancer, colon cancer, and pancreatic cancer and overexpression of $C O X-2$ was reported to be a hallmark of metastatic cancer. ${ }^{17,27}$ Previous studies have reported the relationship between gene expression and lung cancer, and they also found that $C O X-2$ expression was upregulated in lung cancer cells. ${ }^{28,29}$ However, as for the relationship between $C O X-2$ and NSCLC, related research is rare. In this study, we found that $C O X-2$ expression was significantly upregulated in NSCLC cells, which further confirmed that $C O X-2$ can serve as a target gene for treatment of NSCLC. More importantly, studies about resveratrol applied to the treatment of lung cancer have not been developed before, while results in our research proved that resveratrol at a concentration of $60 \mu \mathrm{mol} / \mathrm{L}$ could effectively inhibit the proliferation of NSCLC cells and also can significantly inhibit the malignant proliferation of NSCLC cells, as well as reducing the proportion of NSCLC cells in S phase. In addition, we further confirmed that the mechanism of resveratrol in inhibiting the proliferation of NSCLC cells was through inhibition of the expression of $C O X-2$. This result was consistent with Gong et al research. In their research, they also found that resveratrol could reduce the proliferation rate of colorectal cancer cells by suppressing $\mathrm{COX}-2$ expression. ${ }^{16}$ Another study suggested that the mechanism of overexpressed $C O X-2$ in promoting the proliferation of tumor cells is due to the role of Polygalacturonases (PGs), a product of COX-2 protein metabolism, especially PGE2, which enhances the proliferation of tumor cells. ${ }^{30}$ The increase of PGE2 will not only inhibit the increase of T lymphocytes or B lymphocytes, but also induce the production of immunosuppressive cytokine IL-10. ${ }^{31}$ Therefore, the body's immune surveillance function is decreased, thereby increasing the probability of tumor cells proliferation. Combined with previous studies and the results of this paper, we can further confirm that $C O X-2$ can be used as a therapeutic target for NSCLC, and resveratrol can serve as a new drug for the 


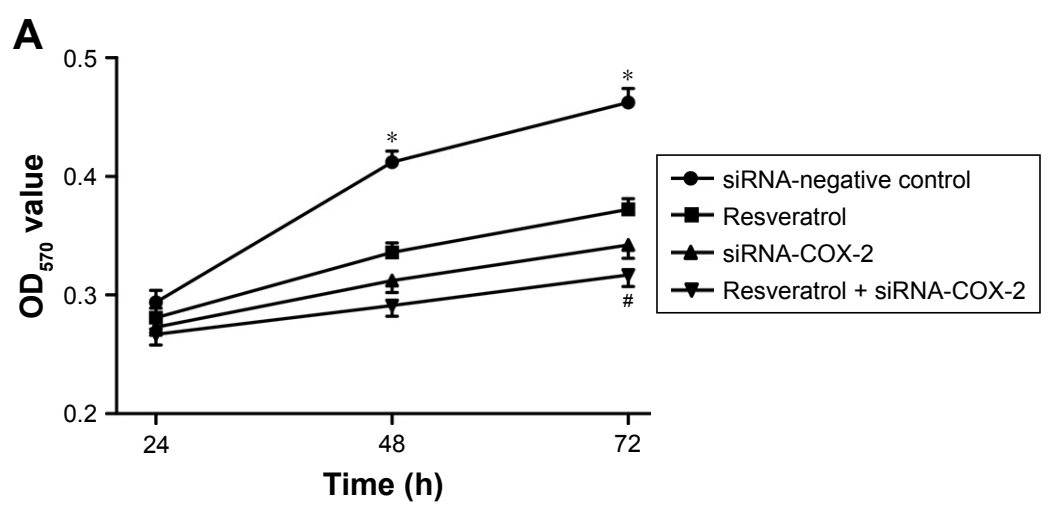

B
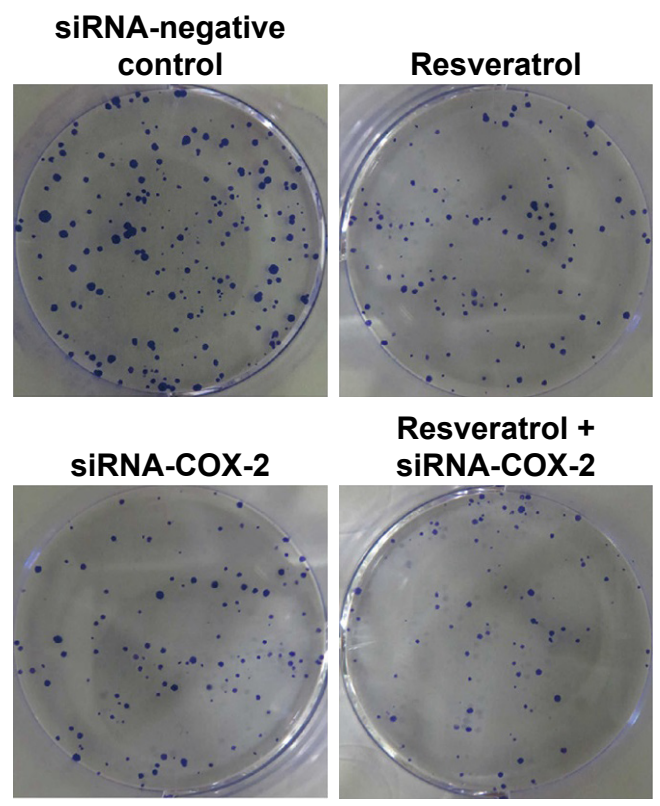

\section{Resveratrol +} SiRNA-COX-2
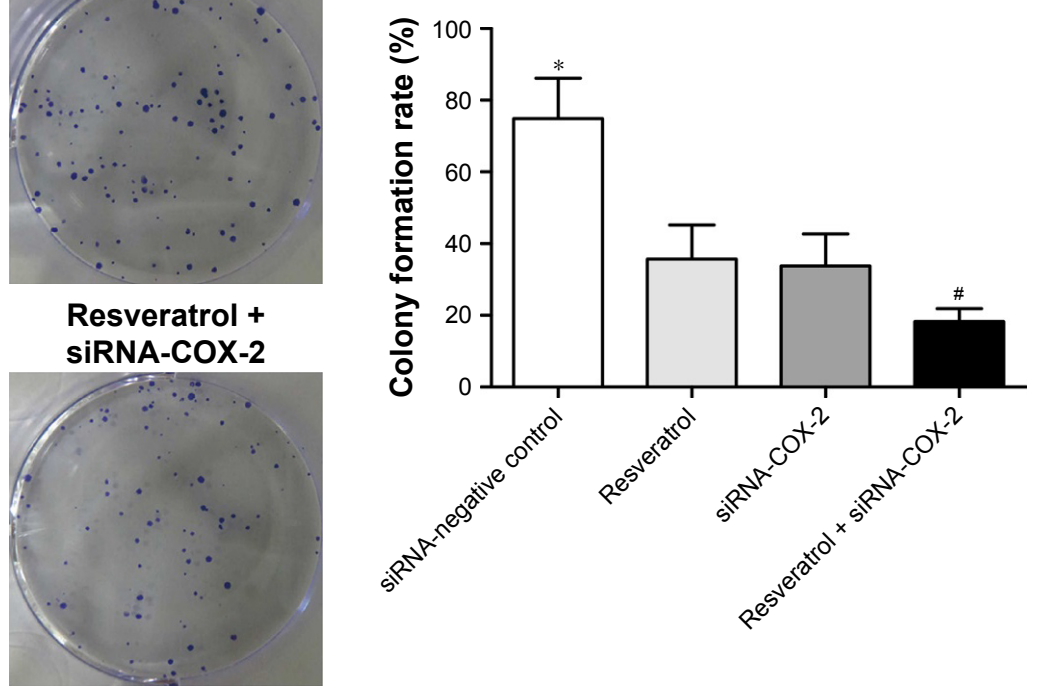

C SiRNA-negative control
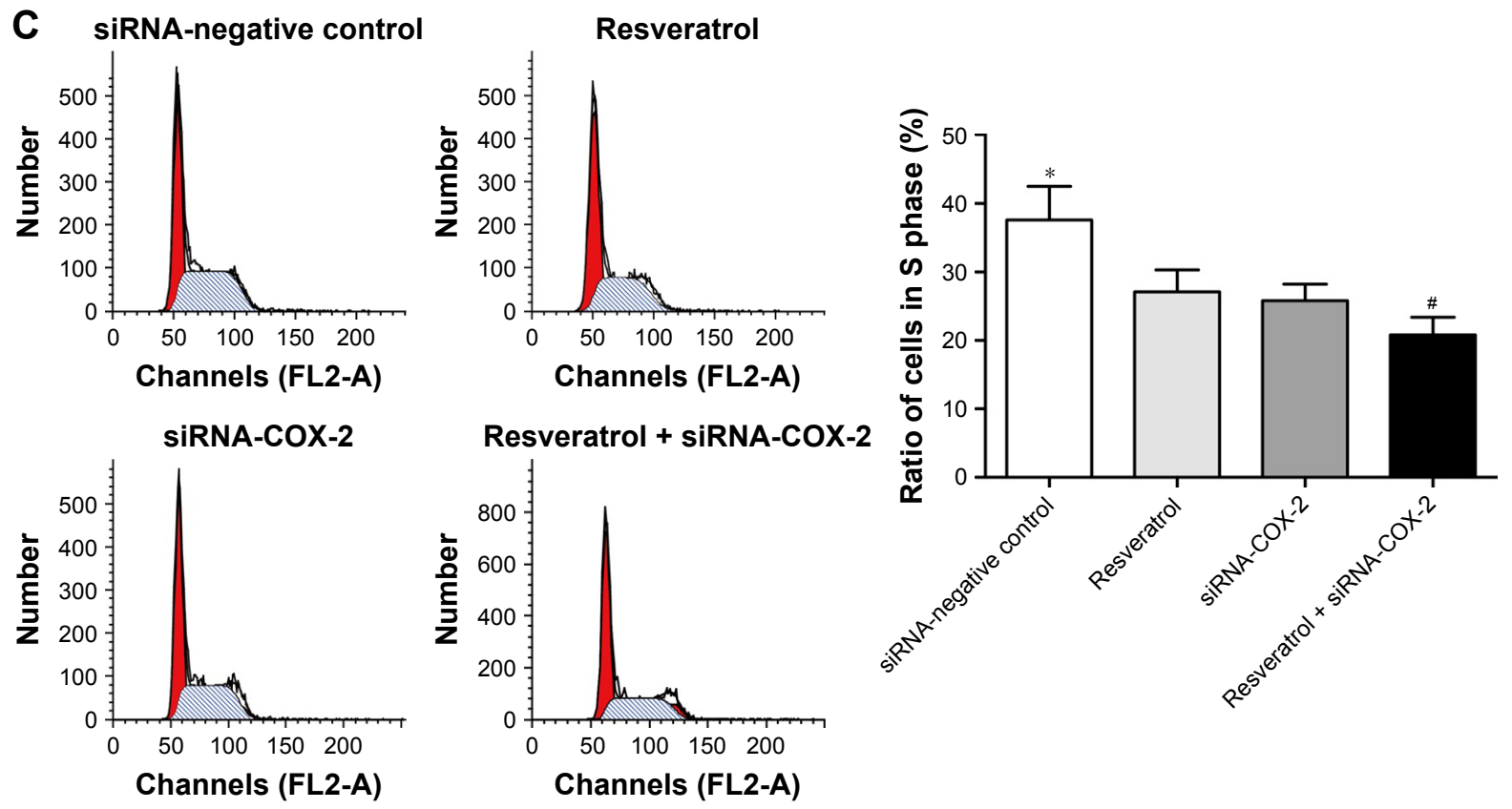

Figure 7 Resveratrol inhibits the proliferation of A549 cells by inhibiting COX-2 expression. (A) Proliferation of A549 cells in each group. (B) Colony formation rate of each group. (C) Ratio of $S$ phase $A 549$ cell in each group. ${ }^{*} P<0.01$ when compared with the other three groups; ${ }^{\# P}<0.05$ when compared with Resveratrol group and siRNA-COX-2 group. 
treatment of NSCLC, which provides an important guiding significance for the treatment of NSCLC clinically.

There are still some limitations in this study. First, in this study, we only conducted the research of resveratrol on A549 cells. Mechanisms of resveratrol on other lung cancer cell lines were not studied because of laboratory condition limitations. Effects of resveratrol on other lung cancer cell lines will be one of the focuses of our future research. Second, the bioavailability of resveratrol in human body was reported very low, even at high doses. ${ }^{32}$ Several studies have shown that nanoscale resveratrol or resveratrol encapsulation could improve its bioavailability. ${ }^{33,34}$ In our future research, methods to improve the bioavailability of resveratrol will also be further studied.

In conclusion, this study showed that resveratrol can inhibit the proliferation of NSCLC cells by inhibiting the expression of $C O X-2$, which provided a new therapeutic target for the future clinical treatment of NSCLC.

\section{Disclosure}

The authors report no conflicts of interest in this work.

\section{References}

1. Gao T, Zhou XL, Liu S, Rao CX, Shi W, Liu JC. In vitro effects of nicotine on the non-small-cell lung cancer line A549. J Pak Med Assoc. 2016;66(4):368-372.

2. Chi F, Wu R, Jin X, Jiang M, Zhu X. HER2 induces cell proliferation and invasion of non-small-cell lung cancer by upregulating COX-2 expression via MEK/ERK signaling pathway. Onco Targets Ther. 2016;9: 2709-2716

3. Rolfo C, Giovannetti E, Hong DS, et al. Novel therapeutic strategies for patients with NSCLC that do not respond to treatment with EGFR inhibitors. Cancer Treat Rev. 2014;40(8):990-1004.

4. Klastersky J, Awada A. Milestones in the use of chemotherapy for the management of non-small cell lung cancer (NSCLC). Crit Rev Oncol Hematol. 2012;81(1):49-57.

5. Bott MJ, Patel AP, Crabtree TD, et al. Role for surgical resection in the multidisciplinary treatment of stage IIIB non-small cell lung cancer (NSCLC). Ann Thorac Surg. 2015;99(6):1921-1928.

6. Bunn PA. Early-stage NSCLC: the role of radiotherapy and systemic therapy. J Natl Compr Canc Netw. 2004;2(Suppl 2):S31-S40.

7. Langhammer S. Rationale for the design of an oncology trial using a generic targeted therapy multi-drug regimen for NSCLC patients without treatment options (Review). Oncol Rep. 2013;30(4):1535-1541.

8. Jing X, Cheng W, Wang S, Li P, He L. Resveratrol induces cell cycle arrest in human gastric cancer MGC803 cells via the PTEN-regulated PI3K/Akt signaling pathway. Oncol Rep. 2016;35(1):472-478.

9. Piotrowska H, Kucinska M, Murias M. Biological activity of piceatannol: leaving the shadow of resveratrol. Mutat Res. 2012;750(1):60-82.

10. Kucinska M, Piotrowska H, Luczak MW, et al. Effects of hydroxylated resveratrol analogs on oxidative stress and cancer cells death in human acute $\mathrm{T}$ cell leukemia cell line: prooxidative potential of hydroxylated resveratrol analogs. Chem Biol Interact. 2014;209:96-110.

11. Aggarwal BB, Bhardwaj A, Aggarwal RS, Seeram NP, Shishodia S, Takada Y. Role of resveratrol in prevention and therapy of cancer: preclinical and clinical studies. Anticancer Res. 2004;24(5A):2783-2840.

12. Sinha D, Sarkar N, Biswas J, Bishayee A. Resveratrol for breast cancer prevention and therapy: preclinical evidence and molecular mechanisms. Semin Cancer Biol. 2016;40-41:209-232.
13. Cao L, Chen X, Xiao X, Ma Q, Li W. Resveratrol inhibits hyperglycemiadriven ROS-induced invasion and migration of pancreatic cancer cells via suppression of the ERK and p38 MAPK signaling pathways. Int $J$ Oncol. 2016;49(2):735-743.

14. Yuan SX, Wang DX, Wu QX, et al. BMP9/p38 MAPK is essential for the antiproliferative effect of resveratrol on human colon cancer. Oncol Rep. 2016;35(2):939-947.

15. Kirkby NS, Chan MV, Zaiss AK, et al. Systematic study of constitutive cyclooxygenase-2 expression: role of NF- $\mathrm{KB}$ and NFAT transcriptional pathways. Proc Natl Acad Sci U S A. 2016;113(2):434-439.

16. Gong WH, Zhao N, Zhang ZM, Zhang YX, Yan L, Li JB. The inhibitory effect of resveratrol on COX-2 expression in human colorectal cancer: a promising therapeutic strategy. Eur Rev Med Pharmacol Sci. 2017;21(5):1136-1143.

17. Güler SA, Uğurlu MÜ, Kaya H, Şen S, Nazlı Y, Güllüoğlu BM. Impact of cyclooxygenase- 2 over-expression on the prognosis of breast cancer patients. Ulus Cerrahi Derg. 2015;32(2):81-88.

18. Ma L, Li W, Wang R, Nan Y, Wang Q, et al. Resveratrol enhanced anticancer effects of cisplatin on non-small cell lung cancer cell lines by inducing mitochondrial dysfunction and cell apoptosis. Int J Oncol. 2015;47(4):1460-1468.

19. Whynott RM, Manahan P, Geisler JP. Vascular endothelial growth factor (VEGF) and cyclooxygenase 2 (COX 2) immunostaining in ovarian cancer. Eur J Gynaecol Oncol. 2016;37(2):164-166.

20. Whyte L, Huang YY, Torres K, Mehta RG. Molecular mechanisms of resveratrol action in lung cancer cells using dual protein and microarray analyses. Cancer Res. 2007;67(24):12007-12017.

21. Yang Q, Xu E, Dai J, et al. A novel long noncoding RNA AK001796 acts as an oncogene and is involved in cell growth inhibition by resveratrol in lung cancer. Toxicol Appl Pharmacol. 2015;285(2):79-88.

22. Nie P, Hu W, Zhang T, Yang Y, Hou B, Zou Z. Synergistic induction of erlotinib-mediated apoptosis by resveratrol in human non-small-cell lung cancer cells by down-regulating survivin and up-regulating PUMA. Cell Physiol Biochem. 2015;35(6):2255-2271.

23. Castro MA, Dal-Pizzol F, Zdanov S, et al. CFL1 expression levels as a prognostic and drug resistance marker in non-small-cell lung cancer. Cancer. 2010;116(15):3645-3655.

24. Wang T, Nelson RA, Bogardus A, Grannis FW Jr. Five-year lung cancer survival: which advanced stage nonsmall cell lung cancer patients attain long-term survival? Cancer. 2010;116(6):1518-1525.

25. Faria AL, Araújo A, Soares M, Azevedo I, da Silva JL. Retrospective study about using topotecan in second-line treatment of small-cell lung cancer. Experience of a single institution, from 2002 to 2006. J Thorac Oncol. 2007;2(8)Suppl 4:S825.

26. Liu CH, Chang SH, Narko K, et al. Overexpression of cyclooxygenase-2 is sufficient to induce tumorigenesis in transgenic mice. J Biol Chem. 2001;276(21):18563-18569.

27. Hang J, Hu H, Huang J, et al. Sp1 and COX2 expression is positively correlated with a poor prognosis in pancreatic ductal adenocarcinoma. Oncotarget. 2016;7(19):28207-28217.

28. Xiao Y, Wang J, Qin Y, et al. Ku80 cooperates with CBP to promote COX-2 expression and tumor growth. Oncotarget. 2015;6(10):8046-8061.

29. Wang J, Xuan Y, Guo W, Du G, Deng W. Abstract 1019: hnRNPA2/ B1 upregulates COX-2 expression and tumor growth and predicts poor prognosis in human lung cancers. Cancer Res. 2015;75(15):1019.

30. Lin YM, Kuo WW, Velmurugan BK, et al. Helioxanthin suppresses the cross talk of COX-2/PGE2 and EGFR/ERK pathway to inhibit Arecoline-induced Oral Cancer Cell (T28) proliferation and blocks tumor growth in xenografted nude mice. Environ Toxicol. 2016;31(12): 2045-2056.

31. Linke B, Schreiber Y, Picard-Willems B, et al. Activated platelets induce an anti-inflammatory response of monocytes/macrophages through cross-regulation of PGE2 and cytokines. Mediators Inflamm. 2017; 2017:1463216.

32. Walle T, Hsieh F, DeLegge MH, Oatis JE, Walle UK. High absorption but very low bioavailability of oral resveratrol in humans. Drug Metab Dispos. 2004;32(12):1377-1382. 
33. Davidov-Pardo G, McClements DJ. Resveratrol encapsulation: designing delivery systems to overcome solubility, stability and bioavailability issues. Trends Food Sci Technol. 2014;38(2):88-103.
34. Neves AR, Martins S, Segundo MA, Reis S. Nanoscale delivery of resveratrol towards enhancement of supplements and nutraceuticals. Nutrients. 2016;8(3):131.

\section{Publish your work in this journal}

OncoTargets and Therapy is an international, peer-reviewed, open access journal focusing on the pathological basis of all cancers, potential targets for therapy and treatment protocols employed to improve the management of cancer patients. The journal also focuses on the impact of management programs and new therapeutic agents and protocols on

\section{Dovepress}

patient perspectives such as quality of life, adherence and satisfaction. The manuscript management system is completely online and includes a very quick and fair peer-review system, which is all easy to use. Visit http://www.dovepress.com/testimonials.php to read real quotes from published authors.

Submit your manuscript here: http://www.dovepress.com/oncotargets-and-therapy-journal 